\title{
Openness and Development or Self-Criticism of Preservice Teachers Watching Videos of Themselves Teaching a Lesson
}

\author{
Gila Cohen Zilka ${ }^{1}$ \\ Correspondence: Bar-Ilan University; Achva Academic College, Israel. \\ Received: July 29, 2020 Accepted: August 24, 2020 Online Published: September 24, 2020 \\ doi:10.5539/res.v12n4p1 URL: https://doi.org/10.5539/res.v12n4p1
}

\begin{abstract}
The goal of videotaping lessons in a teacher training process is to bring about change in the behavior of preservice teachers to promote self-awareness, openness, and development. The research question was whether preservice teachers, after watching the video recordings of the lessons they taught, would undergo a process of development and increased openness, or remain on a plane of self-criticism. The present qualitative discourse analysis study examined the data based on the principles of social and emotional learning (SEL). The data were organized according to SEL categories: self-criticism, self-awareness, self-management, social awareness, interaction management, and accepting responsibility. Participants in the study were 100 preservice teachers studying in teacher training institutions in Israel. Most preservice teachers $(93 \%)$ were found to be critical of themselves, but they also tried to open up to a process of self-awareness (82\%) and to change their behavior. Some participants (11\%) remained "shackled" to their critical attitude and failed to break through the "wall of self-criticism" and change their behavior. Most participants (76\%) showed social awareness and mindfulness of their feelings and of those of others; empathy and ability to read signals sent by their students; listening to others as opposed to being emotionally deaf; attention to the nature of interactions with students during the lesson, to how they moved about the classroom and used their voice, and whether they made eye contact with learners. To bring about change, the teacher must watch, observe, and investigate, and be able to better understand emotional and social situations. Teachers who had experienced social and emotional learning are likely to develop self-awareness and the ability to bring about openness, development, and change in their own behavior and in the behavior of their students.
\end{abstract}

Keywords: teacher education, social and emotional learning (SEL), self-criticism, professional development, self-awareness

\section{Introduction}

Videotaping is used in different ways in the process of instruction of preservice teachers (Borko, Jacobs, Eiteljorg, \& Pittman, 2008; Borko, Koellner, Jacobs, \& Seago, 2011; Lefstein \& Snell, 2011, 2014; Quinn, Schweingruber, Keller, et al., 2011; Sherin, 2004; Sherin \& van, 2009; Zhang, Lundeberg, Koehler, \& Eberhardt, 2011; Zilka 2019). Researchers (Zhang, Lundeberg, Koehler, \& Eberhardt, 2011; Zilka, 2019) have found that watching the videotaped lessons they have taught allowed preservice teachers to observe their behavioral patterns. It placed a mirror in front of them. This process, according to the researchers, may lead to the development of self-awareness. Preservice teachers can watch the recording or sections of the lesson they have taught several times, identify strengths and weaknesses, identify their behavior patterns, understand cause-effect connections, and more.

Preservice teachers who participated in the study were instructed using the social and emotional learning (SEL) method. Before they taught the lessons that were videotaped, they learned how to watch the recordings by watching their teacher's videos. They learned about the stages of reflection and the parameters of observation, such as the nature of interaction with the learners, use of words that express closeness or distance, how a concept or a phenomenon was taught, how they moved around the classroom, the way they used their voice (speaking expressively or flatly, softly or loudly, etc.), whether they made eye contact with learners, and more. From watching their videotaped lessons, preservice teachers could understand how learners see them. Watching in a sheltered place, alone or with a person invited by the preservice teacher, is likely to result in a reflective process and a reshaping of behavioral patterns, without fear of criticism and without the categorization that may arise from criticism voiced by an outside party.

The present study is a follow-up to a previously published mixed-method research (Zilka, 2019), and it deepens the

\footnotetext{
${ }^{1}$ Bar-Ilan University, Lecturer and researcher, the Director of the Department for Teaching Social Science and Communication. Achva Academic College, Head of the program for training tutors and mentors to work with children at risk
} 
understanding of the previous findings using the qualitative and SEL methods. Zilka's (2019) study assessed how videotaping a lesson delivered by preservice teachers affects their reflective process, self-capability, and sense of threat/challenge. The study found that watching videos offered many preservice teachers a chance to observe their own behavior patterns. Some stated that they never thought of themselves as "rigid teachers," "ignoring teachers," teachers who use distancing words and body movements, etc., and watching their videos made them "face themselves," what they referred to as "renewed acquaintance with themselves."

The present study examined whether preservice teachers would experience a process of openness and development, having watched the videotaped lessons they had taught, or remain at the level of self-criticism.

\section{Social and Emotional Learning (SEL)}

Self-criticism can serve as a springboard for change in areas such as responsibility, professionalism, perseverance, and success (Watson \& Greenberg, 2006). But when criticism becomes self-beating, self-condemnation, negative, judgmental, and unforgiving toward the self, it can make one feel diminished, frightened, anxious, and helpless. Some people are not aware of their strong self-criticism. Greenberg and Watson (2006) claimed that change cannot be achieved without self-awareness, self-criticism, and painful feelings.

Self-awareness is a step toward openness and development, but it is necessary to take the four additional steps of SEL to bring about change, openness, and development. Watching a video of oneself may also lead one to self-awareness and to self-criticism.

The preservice teachers who participated in the study learned according to the SEL method. Researchers (Husaj, 2016; Maurice \& Harriett, 2006; Zins, 2004; Zilka, 2017, 2018, 2019, 2020a, 2020b) found that teaching with the SEL method involves five interrelated sets of skills: self-awareness, self-management, social awareness, interaction management, and accepting responsibility. Researchers assumed that social-emotional skills, such as self-esteem, self-awareness, emotion management, assertiveness, independence, self-realization, motivation, empathy, ability to control impulses, self-discipline, perseverance, resilience, relationships and ability to create and maintain them, relationship management, compassion, social responsibility, adaptability, flexibility, problem solving, stress management, stress resistance, delayed gratification, and more, are acquired, that is, they can be learned and practiced.

Self-awareness: awareness of feelings, emotions, desires, needs, actions, behaviors, etc. Not being aware of emotions turns them into central, yet covert, players. The deeper individuals' self-awareness is regarding their emotions, the more confidence they acquire to navigate their life with a sense of exercising free will and free choice. The lack of self-awareness may leave a person at the level of self-criticism. Self-awareness is likely to lead to clarification of emotions that appear dim and elusive. Gradually, one can focus on the emotions, and view them in a clearer and brighter light.

Self-management: awareness, observation, attunement to emotions. Self-management is the ability to be aware of emotions, express them, feel them, dispel them, and navigate around them prudently. Self-management refers to a set of attributes for regulating, assessing, understanding, and managing human emotions and beliefs for oneself and for others, and turning information into useful knowledge that guides and directs one's thinking and actions.

Social awareness: awareness, mindfulness of one's feelings and those of others. Empathy is built on emotional self-awareness and the ability to read signals sent by others, listening to others as opposed to being emotionally deaf.

Interaction management: attention to the nature of interactions with others - cultivating, promoting, abusing, making eye contact, using encouraging or distancing words, and so on. Awareness of emotions, emotion management, and empathy for the emotions of others greatly affect one's relationships with oneself and with others.

Accepting responsibility: decision to change one's behavior in certain aspects that the person finds necessary, and the steps required to implement this decision. It involves consideration of various options for dealing with situations, behaviors, etc. in a different way than the one adopted so far.

Reflective process. Researchers define reflection as contemplation, a conscious thought aimed at bringing about change in behavior (Chittooran, 2015; Hong \& Choi, 2015; Korthagen, 2014; Saperstein, Lilje, \& Seibert, 2015). A reflective process can lead to abstraction, inclusion, identification of behavior patterns, and rebuilding of principles of action in a more effective way than before. Reflection is carried out consciously, in a process of learning and development. A reflective process is a springboard for changing behavior patterns. Reflection on the process of instruction is likely to improve the teaching of a preservice teacher (Beauchamp, 2015; Brophy, 2010; Farr, 2010; Liu, 2015; Murray \& Kujundzic, 2005; Nooreiny, 2007; Shoffner, 2009; Whitton, Sinclair, Barker, Nanlohy, \& Nosworthy, 2004; Zilka, 2019). Studies indicate that the reflective process should be divided into four stages.

Stage 1 - reporting, description of event based on facts and on sequences of events. 
Stage 2 - description of emotions that arose in the course of the event or after it.

Stage 3 - observation of the event, examination of the sequence of events, of a point of crisis during the lesson or a point when motivation increased, etc.; identifying strengths and weaknesses, the patterns of behavior that led to a particular positive or negative situation, trying to understand whether a certain reaction was driven by a hidden motive (such as fear of losing control or lack of mastery of the study material).

Stage 4 - applying judgment and rebuilding. After observing the sequence of events and understanding the cause-effect connections, the preservice teacher raises various options for dealing with these situations in the future, explores the options, tries to understand in depth each option, and examines whether it is suitable and considers what should be done to carry out the chosen option.

Having chosen a preferred option, preservice teachers define milestones for future action that will change their behavior (Beauchamp, 2015; Farr, 2010; Liu, 2015; Murray \& Kujundzic, 2005; Nooreiny, 2007; Shoffner, 2009; Whitton, Sinclair, Barker, Nanlohy, \& Nosworthy, 2004). The reflective process is subjective, and in the course of it individuals consciously examine emotions, feelings, fears, and thoughts that arise in them, and decide how they will work in the future.

\section{Videotaping Preservice Teachers' Lessons During Their Studies Toward Receiving a Teaching Certificate}

How can recording the lesson being taught benefit the instructors? Researchers (Zhang, Lundeberg, Koehler, \& Eberhardt, 2011; Zilka, 2019) found that viewing a videotaped lesson was rated as most helpful by participants. Among the benefits mentioned was the reflection process prompted by the viewing. Watching the video recording of the lesson enabled viewers to pay attention to events that they overlooked in real time, making possible more objective self-perception.

Researchers (Sherin, 2004; Sherin \& van, 2009; Zhang, Lundeberg, Koehler, \& Eberhardt, 2011; Zilka, 2019) found that when a lesson is videotaped, the viewers do not rely only on what they remember or allow themselves to remember, but are given the opportunity to view the lesson in its entirety and analyze the sequence of events, their own behavior and that of others, and the nature of the interactions that took place during the lesson they taught. Preservice teachers can choose what to observe, without worrying about missing anything, and can go back and forth, each time choosing to focus on another aspect. The replay of a video allows the preservice teacher to deal with various aspects in a protected place, without pressure, and to watch various sections repeatedly. The present study examined whether preservice teachers experienced a process of openness and development following the viewing of videotaped lessons they taught, or whether they remained on the plane of self-criticism.

\section{The Purpose of the Study}

The purpose of videotaping lessons as part of teacher training was to bring about a change in preservice teachers' behavior, resulting in greater openness and development, and awareness of their inherent powers. . Watching a video of a lesson they taught, in a secure location chosen by themselves, enabled preservice teachers to engage in self-contemplation without fear of interfering environmental factors.

This qualitative study evaluated the data based on the principles of SEL, using the SEL categories: self-criticism, self-awareness, self-management, social awareness, interaction management, and accepting responsibility.

\section{The Importance of the Study}

The emphasis of this study was on the construction of the identity of preservice teachers who were going to work with children, educating and teaching them. In the process of working with children, the teachers must address emotional and social aspects, their own and their students'. To bring about change, the teacher must watch, observe, and investigate, to be able to better understand emotional and social situations.

\section{Method}

Sample

Participants were 100 preservice teachers in their senior year of studies toward a teaching certificate, who studied at the same time in four groups at two teacher training institutions in Israel: 41 were male, 59 female; $65 \%$ were below and the rest over the age of 30 .

Discourse analysis was conducted according to the approach described by Adler and Adler (2008), Atkinson and Delamont (2006), and Hammersley (2008). After initial processing, responses were sorted, distinct elements were identified, and themes were formulated. The data were organized according to SEL categories: self-criticism, self-awareness, self-management, social awareness, interaction management, and accepting responsibility.

Because the SEL categories are interrelated, the method and the findings sections were reviewed by five Institutional Review Board (IRB) experts who approved the study. Each category and topic is illustrated below by excerpts. 


\section{Research process}

The research was conducted in the final year of preservice teachers' study course toward a teaching certificate. All participants had a bachelor's degree in social sciences, and some also had a master's degree (32\%) or a Ph.D (20\%). Twenty respondents out of those who completed the questionnaires were interviewed. The data were collected in 2018-2019.

\section{Research tool}

The questionnaire, based on Zilka (2017, 2019) and Zilka et al., (2019). contained 20 open-ended questions and statements to complete, as listed below:

1. When watching the recordings of the lessons you taught, what attracted your attention (for example: professional knowledge, the teaching method you chose, interaction with learners, body language, use of voice during the lesson, your movement across the classroom during the lesson, etc.)?

2. What did you feel as a result of watching the recordings of the lessons you taught (for example: satisfaction, empowerment, being strengthened/weakened, anger, etc.)?

3. Describe the most meaningful experience you had during the lesson you taught.

4. Describe the most significant experience you had while watching the videos.

5. Following the video I learned about myself that...

6. The video clarified for me that...

7. The hardest part for me was...

8. While watching the videos I felt frustration/anger/discomfort...

9. I felt that my weak point was ...

10. How did you feel/act as a result of these feelings?

11. Do you think it is important to videotape lessons in a microteaching course?

\section{Findings}

The findings are presented according to the SEL categories of self-criticism, self-awareness, self-management, social awareness, interaction management, and accepting responsibility.

\section{Self-criticism}

Ninety-three participants (out of 100) completed the sentences indicating they felt self-critical. Eleven preservice teachers reported only self-criticism, and did not report self-awareness, self-management, social awareness, interaction management, or accepting responsibility, throughout the questionnaire.

Body language was the topic mentioned frequently with regard to self-criticism.

From the responses and the completed statements, it emerged that self-criticism focused on the respondents' judgmental attitude toward themselves.

Sample quotes:

"I felt embarrassed and angry at myself for not remembering all the material because of the pressure."

"I felt very angry because I made mistakes as I didn't concentrate. If I were more concentrated I would not have made them. Lack of concentration is my biggest problem in life that has been with me since I can remember myself."

"What caught my attention were my hand movements. I was unaware that I was using so many hand movements. I couldn't break away from the video, watching my hand movements over and over again. I felt very frustrated."

"The most difficult experience was watching my motion in the classroom, and especially the involuntary movements."

"I found out I was officious while teaching, mechanical like a puppet on a string. I was disappointed in myself."

"I saw that I use my hands too much. I don't always stand straight enough (even when I think I do). It's a shame."

"They see everything. I'm really transparent when I'm in front of the class."

"I found that there was a big gap between how I thought I taught and what I saw in the videos. I felt the feedback I received from the students was justified because I really didn't teach well."

"The hardest part for me was watching the videotaped feedback from other students. I felt the feedback was not exhaustive, and that was because the lesson was not structured properly. I could have planned the lesson differently, and 
so I felt unsatisfied because of the blunder."

"I felt ashamed and uncomfortable with the way I presented at the lesson."

"I felt angry about not being relaxed in class. I was like a robot."

"I felt uncomfortable watching the videos, I felt very disappointed. A feeling of exposure, shame, great frustration."

"I felt frustrated because I saw myself getting confused, out of focus."

"I mostly felt frustrated by my outward appearance. I looked unkempt. It was hard for me to look at myself."

\section{Self-awareness}

Eighty-two respondents (out of 100) completed the sentences indicating that they felt self-conscious. In this category, preservice teachers responded in a way that shows a process of awareness of their emotions and feelings.

Sample quotes:

"From watching the video, I realized that my explanations needed polishing."

"I was talking too fast, trying to jam a lot of material in a short time."

"I've learned that I need to improve my hand gestures when standing in front of an audience."

"I learned what my weaknesses and strengths were, what I needed to improve in my teaching skills, and what I looked like."

"I'm too frantic and I need to work on my body language."

"Suddenly I noticed that I was dragging my feet. I felt awful, but I'd like to pay attention to it next time."

\section{Self-management}

Seventy-three respondents (out of 100) completed the sentences indicating that they had come to the conclusion that they should manage themselves differently. The ideas that came up in this category were awareness of openness, the ability to express one's emotions and difficulties, and to dissipate them, and the need to move wisely in a new direction.

Sample quotes:

"What mainly attracted my attention was my body language and eye contact with the students. I didn't really look at the students. I looked into the classroom. I found I was constantly swinging. My body language was causing attention problems. I must maintain eye contact with the class and stop swinging all the time. It's very difficult for anyone watching me."

"I felt I still needed to work on my being in front of the classroom."

"From watching my video, I noticed how I looked to the outside, what I should improve and strengthen, and what I should continue doing. It was a truly meaningful experience to see myself from the outside and understand how others are experiencing me. It certainly helped me realize how to teach better next time."

"When watching the videos, I felt embarrassed, stressed, sometimes confused... And then it receded, and I felt clearer to myself, and where I want to go, how to improve."

\section{Social awareness and interaction management}

Seventy-six preservice teachers (out of 100) completed the sentences indicating that they felt social awareness and experienced interaction management. They experienced social awareness and mindfulness of their own feelings and of those of others. Empathy and ability to read signals projected by students (other preservice teachers), attentiveness to others, as opposed to emotional deafness, paying attention to the nature of interaction with students during the lesson, to how they moved around the classroom, how they used their voice, whether they made eye contact with learners, and more.

Sample quotes:

"The way I taught the study material surprised me, and also the way I conducted a dialogue with the students. I thought I was interacting, but from watching the videos it became clear that I asked very knowledge-focused questions without allowing any discussion."

"Suddenly I saw that the teaching method I chose did not encourage participation. The lesson was very boring."

"My body language made me realize that I projected insecurity. Maybe that's why there were problems with discipline, because I projected insecurity by my body language."

"I saw in the video that when I heard noise and conversation during the lesson, it made me angry and I reprimanded the 
students in an angry tone. I realized that my reaction caused more severe problems with discipline than before I scolded students about their behavior in an angry way."

"I used to be an athlete, and while watching the videos of my lessons I felt like athletes watching their own performance. I realized things I was unaware of before watching, such as my speech fluency, my problem allowing space for students, and my desire to teach everything I had prepared in advance."

"Watching the movie I saw that I was very disturbed during the lesson by students being engaged with their laptops. I interpreted it as lack of interest in my lesson. After watching over and over again I realized their difficulty in resisting temptation. Of course, I realized that this is how I behave in class, too: I deal with the computer, check Facebook and email, and even prepare other courses."

\section{Accepting responsibility}

Sixty-eight preservice teachers (out of 100) completed the sentences indicating that they accepted responsibility and made a decision to engage in the process of change and development.

Sample quotes:

"At first I felt embarrassed and even stressed, but after the first viewing, I felt mostly able and satisfied, having realized what I could improve or do things differently."

"The insecurity I have is legitimate, but I need to be prepared and open to what will develop during the lesson. I realized that my challenge now is to strengthen myself to feel self-confident and to project professionalism in the classroom."

"I was in shock when I saw in the video that some students began to misbehave as a result of the way I taught the topic of the lesson. They said things I didn't pay attention to at the time of the lesson, but couldn't ignore them when watching the video. I suddenly realized that all the trouble was because of what I said and because I didn't let the students talk, and not because they wanted to hurt me, as I felt during the lesson."

"I saw myself standing crouched. I was very disappointed and decided to practice standing straight."

"I decided I wanted to pay attention to my posture and my body movements during the lesson, so that I would stop dragging my feet and overcome my shyness."

"I realized that I had to work on my voice, raise my voice occasionally, because I realized that the teacher's voice is very important, and that there is a connection between the use of voice and the behavior of the students."

"As a result of watching, I was surprised by my posture during the lesson. I didn't realize that this was how I looked. That's why I read about the subject and did some internal work to improve my posture."

There were some additional data. Some preservice teachers mentioned other feelings in connection with the questions asked in the questionnaire, therefore the answers add up to more than 100:

1. Data processing results revealed no differences between genders or age groups.

2. Body language. All participants in the study (100 preservice teachers) stated that their body language attracted their attention when they were watching the recordings of the lessons they had taught.

3. Speech. Twenty-eight participants stated that the style of speech and the use of voice during the lesson attracted their attention.

4. Satisfaction. Thirty six preservice teachers stated that they felt satisfied.

5. Feeling empowered. Eighteen preservice teachers stated that they had felt empowered.

6. Feeling fortified. Eighteen preservice teachers stated that they had felt fortified.

7. Feeling angry. Fifteen preservice teachers mentioned anger.

8. Feeling weakened. Sixteen preservice teachers stated that they had felt weakened.

9. Feeling embarrassed. Thirty two preservice teachers stated that they had felt embarrassed.

10. Feeling pressured. Sixteen preservice teachers stated that they had felt pressured.

\section{Discussion}

This study examined whether preservice teachers experience a process of openness and development after watching a videotaped lesson they taught, or remain on a plane of self-criticism? The purpose of videotaping lessons in the process of training teachers is to allow the development of emotional and social aspects of the preservice training process, to bring about a change in preservice teachers' behavior toward openness and development, and to realize their inherent powers, believing that the person can change, open, and develop. Watching video recordings of the lessons they taught, 
in a sheltered location chosen by them, allows student to engage in self-scrutiny without fear of environmental factors interfering.

The findings of this study revealed that most preservice teachers (93 out of 100 participants) were critical of themselves, yet most (82 out of 100 participants) attempted to open up to a process of self-awareness and to change their behavior. Some participants (11 out of 100) remained "stuck" and failed to break through the "wall of self-criticism" and engage in a process of change, openness, and development. These findings reinforce the claims of Watson and Greenberg (2006) that it is possible to bring about change in the degree of self-criticism and self-beating. Self-awareness is likely to arouse in a person a desire for change and for initiating a process of openness and self-development. The findings showed that watching the video of oneself influenced some of the preservice teachers and led to self-awareness.

\section{Body Language}

One of the issues that stood out and repeatedly came back in participants' responses was body language. How do I present to the world? How do others see me? How do I use my body to convey messages, to introduce myself? Several preservice teachers mentioned that they were unaware of the importance of their body language during the lesson or of teachers' body language in general. Some of them felt embarrassed. One preservice teacher wrote:

"When I was watching the videos, it was hard for me to see how everyone was looking at me. I felt examined."

Preservice teachers mentioned especially their posture; some were surprised to find that they were slouching, that their body was limp, etc. Body language was the topic that came back often in the context of self-criticism. Fidgeting, body movements that project stress, swaying from side to side, involuntary and incessant hand movements, slumping over, too low or too stiff muscle tone, hanging one's head, staring into the classroom space instead of looking at the class, uncontrolled facial expressions, etc., create the impression of a teacher who feels restless, fearful, stressed, and insecure. Because our body movements and posture are in one way or another affected by our emotional state, our self-esteem, and naturally, our psychological makeup, one's movement and posture reflect on one's emotions regarding oneself, and regarding oneself in interaction with others. To project a different impression, the preservice teachers must come prepared to the lesson, which is likely to make them feel more at ease, more flexible in their responses, and less concerned with those who look at them. In addition, movement, stature, and body posture are expressions of various aspects of the human soul that have evolved throughout the individual's life. Greenberg and Watson (2006) stated that change can be achieved if there is self-awareness. Self-awareness is a step toward openness and development, and watching a video of oneself may bring preservice teachers to awareness of their own body language. To change body posture may require a change in one's attitude toward oneself and toward those around, and the practice of dynamic movements that convey confidence, instead of fidgety movements behind the teacher's desk or close to the blackboard. Practicing dynamic movement may have an effect on the person's perception of oneself and of oneself in interaction with others.

\section{Self-Criticism, Self-Awareness, Self-Management, and Accepting Responsibility}

Ninety-three preservice teachers (out of 100) completed the statements indicating that they felt self-critical. Eleven respondents reported only self-criticism, and did not report on self-awareness, self-management, social awareness, interaction management, and assuming responsibility throughout the entire questionnaire.

From the responses and the completion of sentences, it transpired that self-criticism focused on the respondents' judgmental attitude toward themselves.

Sample quotes: "I noticed my body language, I was really unaware of how I was moving in space. When a teacher gives a lesson, it is very important what he project with his body language. I feel a real failure. I felt ashamed to go back to class and see the students I had taught."

"I felt uncomfortable watching myself, to see 'face to face' my weaknesses. It was very embarrassing, and I felt frustrated when I saw with my own eyes the weak points that I thought I had already resolved. I felt very angry with myself."

"I saw that I didn't succeed to change over time, that I broadcast weakness, anemia, that I have a weak self-image and it's difficult for me to stand in front of an audience."

Greenberg and Watson (2006) claimed that self-criticism may be a springboard for change in areas such as accepting responsibility, professionalism, perseverance, and success. But when criticism becomes self-loathing, self-condemnation, negative, judgmental, and an unforgiving attitude toward oneself, it can make one feel weakened, scared, anxious, and helpless, instead of paving the way to self-awareness, openness, and development, and bring about a change in one's behavior. As some people are not at all aware of their strong self-criticism, watching a video recording of oneself may make the viewers aware of their self-criticism. The preservice teachers must observe their behavior to provoke self-criticism and painful feelings, increase self-awareness, so that change may become possible. Self-awareness refers to 
awareness of our emotions and feelings. Lack of self-awareness may cause an individual to remain in the plane of self-criticism. The higher awareness individuals achieve of their emotions, the better they can navigate their life with the confidence of exercising free will and free choice.

Eighty-two respondents (out of 100) provided answers and completed the statements indicating that they felt self-aware. In this category, respondents provided answers attesting to having awareness of their emotions and feelings.

Sample quotes:

"I was surprised, I saw that I spoke too quickly and realized that I needed to improve it to be more understandable."

"I have to improve the way I listen to students in class and how I should respond to them. I was surprised by what I saw."

Individuals' self-awareness may lead to a decision to change the behavioral patterns that have emerged throughout their life, a change in their attitude toward themselves and toward those around them, and a change in their behavior management: self-management and accepting responsibility, in the sense of being aware of one's emotions, express them, feel them, dispel them, and navigate wisely. In these categories, awareness rises to the state of openness, the ability to express one's feelings and hardships, dispel them, and move wisely in a new direction, to exercise judgment and to reform responses and behavior. After looking at the sequence of events and understanding the cause-effect connections between them, preservice teachers raised various options for dealing with these situations in the future, explored the options, sought to understand in-depth each option and examine whether it was suitable and what should be done to implement it. Having determined a preferred course of action, preservice teachers defined milestones for future action that would change their behavior.

The following excerpts illustrate these ideas: "In terms of professional knowledge, I felt I was ready, but I could arrange the parts of the lesson in a more organized and clear way." "From watching the videos I realized that I had to deepen my knowledge before teaching a class."

The findings of the study are similar to those of previous research findings (Chittooran, 2015; Hong \& Choi, 2015; Husaj, 2016; Korthagen, 2014; Maurice \& Harriett, 2006; Saperstein, Lilje, \& Seibert, 2015; Zilka, 2019; Zins, 2004). The emphasis in this study was on building the identity of preservice teachers who are going to work with children, educating and instructing them. In the process of working with children, teachers must address emotional and social aspects; involve children in emotional, social, value-based learning and experiences; translate values into everyday behaviors in matters that are relevant to their world; and foster in children awareness of their own feelings and feelings of others, by promoting their ability to express emotions. Therefore, at the time of their professional training, preservice teachers must be exposed to social-emotional learning and experiences. Students in teacher training programs are future teachers, and as such they should demonstrate these skills in their dealings with children and with school staff, and foster these skills in their students. SEL is an arena that serves as a training ground for preservice teachers' social development, as an integral part of their spiritual wellbeing, cognitive development, and expansion of their knowledge space.

\section{Social Awareness and Interaction Management}

Social awareness refers to the mindfulness of our feelings and those of others. Empathy is built on emotional self-awareness and the ability to read signals sent by others, listening to others as opposed to being emotionally deaf; attention to the nature of interactions with students during the lesson; using encouraging or distancing language; the way preservice teachers learn a concept or phenomenon; how they move about the classroom; how they use their voice (speaking quietly, loudly, etc.); whether they make eye contact with learners, and more.

Seventy-six participants (out of 100) completed the statements related to social awareness and interaction management. They showed social awareness and mindfulness of their feelings and of those of others; empathy and ability to read signals sent by their students; listening to others as opposed to being emotionally deaf; attention to the nature of interactions with students during the lesson, to how they moved about the classroom and used their voice; whether they made eye contact with learners, and more. Sample excerpts: "While watching, I realized that the students made comments not because they were trying to trip me, as I felt during the lesson, but because they could not understand the material I was teaching. After watching, I realized that I was focusing on the definitions that I was teaching and didn't notice that the students didn't understand what I was saying. They wanted to understand, that I give them examples. " "From watching the videos, I realized the importance of engaging the audience to participate, of thinking about how questions should be asked, of preparing ahead of time for 'emergencies,' of being prepared for questions and knowing how to explain the study material in the best way."

The emphasis of this study was on the construction of the identity of preservice teachers who are going to work with children. The children's self-image and self-confidence are greatly influenced by social connections with their peers. Relationships are at the basis of social belonging, which is essential for the children's development. To be able to bring about change, teachers must realize what their own needs are and what the needs of others are, to be researchers, to 
observe, and to understand emotional and social situations better. The more teachers identify the different pressures they and others are coping with, and how these pressures affect them and their attitude (likewise, how they affect others and their attitude), the more likely they will be to develop empathy toward themselves and toward others, and understand the reasons behind behaviors. As noted above, social-emotional skills are acquired, and can be learned and practiced (Husaj, 2016; Maurice \& Harriett, 2006; Zins, 2004). It is important to provide children with an environment that encourages the feelings of belonging and being protected, and facilitates growth, interest, ability, challenge, success, and feedback; an environment that allows for meaningful interaction, positive experiences, and success; an environment that encourages social connectedness through experiences that create a sense of belonging, involves children in meaningful interactions that lead to meaningful and engaged roles at home, school, and community (Birch \& Ladd, 1997; Huppert, Baylis, \& Keverne, 2005; Romi, Savicki, Grupper, \& Caspi , 2007; Zilka, 2017, 2018).

\section{Conclusion}

The emphasis of this study was on the construction of the identity of preservice teachers who are going to work with children, educating and teaching them. In the process of working with children, the teachers must address emotional and social aspects, their own and their students'. To bring about change, the teacher must watch, observe, and investigate, to better understand emotional and social situations. Teachers who had experienced social emotional learning may have developed self-awareness and the ability to bring about openness, development, and change in their own behavior and in the behavior of their students.

\section{Limitations of the Study and Future Research}

There is a need for a comprehensive study of teachers' body language and the connection between it and the ability of teachers to affirm authority in the classroom, including maintaining discipline. This issue came up prominently in the data of the present study, but because the topic was not initially defined as the object of the study, there was no focused data collection to investigate this connection, and therefore the study cannot report on this issue.

\section{References}

Adler, P. A., \& Adler, P. (2008). Of Rhetoric and Representation: The Four Faces of Ethnography. The Quarterly Sociological, 49(1), 1-30. https://doi.org/10.1111/j.1533-8525.2007.00104.x

Atkinson, E., \& Delamont, S. (2006). In the roiling smoke: qualitative inquiry and contested fields. International Journal of Qualitative Studies in Education, 19(6), 747-755. https://doi.org/10.1080/09518390600975974

Beauchamp, C. (2015). Reflection in teacher education: issues emerging from a review of current literature. International and Multidisciplinary Perspectives, 16(1), 123-141. https://doi.org/10.1080/14623943.2014.982525

Borko, H., Jacobs, J., Eiteljorg, E., \& Pittman, M. E. (2008). Video as a tool for fostering productive discussions in mathematics professional development. Teaching and Teacher Education, 24(2), 417-436. https://doi.org/10.1016/j.tate.2006.11.012

Borko, H., Koellner, K., Jacobs, J., \& Seago, N. (2011). Using video representations of teaching in practice-based professional development programs. ZDM Mathematics Education, 43, 175-187. https://doi.org/10.1007/s11858-010-0302-5

Brophy, J. E. (2010). Motivating students to learn. Routledge Bryk, A. S. (2009). Support a science of performance improvement. Phi Delta Kappan, 90, 597-600. https://doi.org/10.1177/003172170909000815

Chittooran, M. M. (2015). Reading and writing for critical reflective thinking. New Directions for Teaching and Learning, 143, 79-95. https://doi.org/10.1002/t1.20137

Farr, F. (2010). The discourse of teaching practice feedback: A corpus-based investigation of spoken and written modes. London: Routledge. https://doi.org/10.4324/9780203846742

Greenberg, L. S., \& Watson, J. C. (2006). Emotion-focused therapy for depression. American Psychological Association. https://doi.org/10.1037/11286-000

Hammersley, M. (2008). Questioning Qualitative Research: Critical Essays. London, UK: Sage. https://doi.org/10.4135/9780857024565

Hong, Y. C., \& Choi, I. (2015). Assessing reflective thinking in solving design problems: The development of a questionnaire. British Journal of Educational Technology, 46(4), 848-863. https://doi.org/10.1111/bjet.12181

Huppert, F., Baylis, N., \& Keverne, B. (2005). The science of well-being. Oxford University Press. https://doi.org/10.1093/acprof:oso/9780198567523.001.0001

Husaj, S. (2016). Social Emotional Learning (SEL). European Journal of Multidisciplinary Studies, 1(3), 168-171. 
https://doi.org/10.26417/ejms.v1i3.p168-171

Korthagen, F. A. J. (2014). Promoting core reflection in teacher education: Deepening professional growth. International Teacher Education: Promising Pedagogies (Part A) Advances in Research on Teaching, 22, 73-89. https://doi.org/10.1108/S1479-368720140000022007

Lefstein, A., \& Snell, J. (2014). Better than Best Practice: Developing Dialogic Pedagogy. London: Routledge. https://doi.org/10.4324/9781315884516

Lefstein, L., \& Snell, J. (2011). Professional vision and the politics of teacher learning. Teaching and Teacher Education, 27, 505-514 .https://doi.org/10.1016/j.tate.2010.10.004

Liu, K. (2015). Critical reflection as a framework for transformative learning in teacher education. Educational Review, 67(2), 135-157. https://doi.org/10.1080/00131911.2013.839546

Maurice, J. E., \& Harriett, A. (Ed.). (2006). The Educator's Guide to Emotional Intelligence and Academic Achievement Social-Emotional Learning in the Classroom. Saga Corwinpress, California.

Murray, M., \& Kujundzic, M. (2005). Critical reflection: A textbook for critical thinking. Que'bec, Canada: McGill-Queen's University Press.

Nooreiny, M. (2007). Telling his or her story through reflective journals. International Education Journal, 8(1), 205-220.

Quinn, H., Schweingruber, H., Keller, T., \& al. (2011). A framework for K-12 science education: Practices, crosscutting concepts, and core ideas. National Academies Press.

Romi, S., Savicki, V., Grupper, E., \& Caspi, R. (2007). Occupational burnout among child welfare workers: A work-setting comparison. International Journal of Child and Family Welfare, 10(3-4), 93-109.

Saperstein, A. K., Lilje, T., \& Seibert, D. (2015). A model for teaching reflective practice. Military Medicine, 180(4), 142-146. https://doi.org/10.7205/MILMED-D-14-00589

Sherin, M. (2004). New Perspectives on the role of video in teacher education. Using video in teacher education. Advances in research on teaching, 10, 1-27. https://doi.org/10.1016/S1479-3687(03)10001-6

Sherin, M. G., \& van Es, E. A. (2009). Effects of Video Club Participation on Teachers' Professional Vision. Journal of Teacher Education, 60, 20-37. https://doi.org/10.1177/0022487108328155

Shoffner, M. (2009). The Place of the Personal: Exploring the Affective Domain through Reflection in Teacher Preparation. Teaching and Teacher Education: An International Journal of Research and Studies, 25(6), 783-789. https://doi.org/10.1016/j.tate.2008.11.012

Whitton, D., Sinclair, C., Barker, K., Nanlohy, P., \& Nosworthy, M. (2004). Learning for teaching: Teaching for learning. Southbank, Victoria: Thomson Learning.

Zhang, M., Lundeberg, M., Koehler, M. J., \& Eberhardt, J. (2011). Understanding affordances and challenges of three types of video for teacher professional development. Teaching and Teacher Education, 27, 454-462. https://doi.org/10.1016/j.tate.2010.09.015

Zilka, C. G. (2017). The Elements Way: Empowering parents, educators, and mentors in the age of new media. Issues in Informing Science and Information Technology, 14, 101-119. https://doi.org/10.28945/3702

Zilka, C. G. (2018). Working with immigrant children and adolescents at risk: Mentors' use of The Elements Way. Psychology Research, 8(7), 308-321. https://doi.org/10.17265/2159-5542/2018.07.003

Zilka, C. G. (2019). Reflective process of pre-service teachers who watch video recordings of lessons they taught. Journal of Educational Technology, 16(3), 7-20. https://doi.org/10.26634/jet.16.3.16412

Zilka, C. G. (2020a). Social presence in blended course forums in the training of preservice teachers. International Journal of Mobile and Blended Learning (IJMBL), 12(4), Article 2.

Zilka, C. G. (2020b). The experience of receiving and giving public oral and written peer feedback on the teaching experience of preservice teachers. In M. Jones (Ed.), Proceedings of InSITE 2020: Informing Science and Information Technology Education, pp 1-13. Informing Science Institute. https://doi.org/10.28945/4502

Zilka, C. G., Rahimi, D. I., \& Cohen, R. (2019). Sense of challenge, threat, self-efficacy, and motivation of students learning in virtual and blended courses. American Journal of Distance Education, 33(1), 2-15. https://doi.org/10.1080/08923647.2019.1554990.

Zins, J. E. (Ed.). (2004). Building Academic Success on Social and Emotional Learning: What Does the Research Say? 
(The Series on Social Emotional Learning). Teachers College Press, New-York \& London.

\section{Copyrights}

Copyright for this article is retained by the author(s), with first publication rights granted to the journal.

This is an open-access article distributed under the terms and conditions of the Creative Commons Attribution license (http://creativecommons.org/licenses/by/4.0/). 